OPEN

SUBJECT AREAS:

METALLOPROTEINS

HYDROLASES

KINETICS

PHOSPHORYLATION

Received

17 April 2013

Accepted

24 June 2013

Published

1 August 2013

Correspondence and requests for materials should be addressed to W.C. (w.chen@duke. edu) or J.-P.S. (sunjinpeng@sdu.edu. cn)

\section{Cadmium is a potent inhibitor of PPM phosphatases and targets the MI binding site}

Chang Pan ${ }^{1,2}$, Hong-Da Liu' ${ }^{1}$ Zheng Gong ${ }^{1,3}$, Xiao Yu' ${ }^{4}$ Xu-Ben Hou ${ }^{5}$, Di-Dong Xie ${ }^{1,6}, X_{i}-B i n ~ Z h u^{4}$,

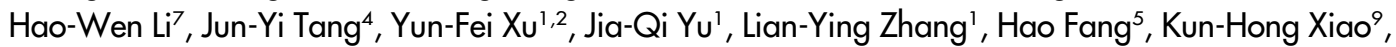
Yu-Guo Chen ${ }^{2}$, Jiang-Yun Wang ${ }^{8}$, Qi Pang ${ }^{1,6}$, Wei Chen ${ }^{7} \&$ Jin-Peng Sun ${ }^{1,6}$

'Key Laboratory Experimental Teratology of the Ministry of Education and Department of Biochemistry and Molecular Biology, Shandong University, School of Medicine, Jinan, Shandong 250012, China, ${ }^{2}$ Qilu Hospital, Shandong University, Jinan, Shandong 250012, China, ${ }^{3}$ Weihai campus, Shandong University, Weihai, Shandong 264209, China, ${ }^{4}$ Department of Physiology, Shandong University, School of Medicine, Jinan, Shandong 250012, China, ${ }^{5}$ School of Pharmaceutical Sciences, Shandong University, Jinan, Shandong 250012, China, 'Shandong Provincial Hospital, Shandong University, Jinan, Shandong 250012, China, ${ }^{7}$ Laboratory of Clinical Medical Research, Beijing Tiantan Hospital, Capital Medical University, Beijing 100050, China and Department of Medicine, Duke University Medical Center, Durham, NC 27710, USA, ${ }^{8}$ Institute of Biophysics, Chinese Academy of Sciences, Beijing, ${ }^{9}$ Department of Medicine, Duke University Medical Center, Durham, North Carolina 27710, USA.

The heavy metal cadmium is a non-degradable pollutant. By screening the effects of a panel of metal ions on the phosphatase activity, we unexpectedly identified cadmium as a potent inhibitor of PPM1A and PPM1G. In contrast, low micromolar concentrations of cadmium did not inhibit PP1 or tyrosine phosphatases. Kinetic studies revealed that cadmium inhibits PPM phosphatases through the M1 metal ion binding site. In particular, the negative charged D441 in PPM1G specific recognized cadmium. Our results suggest that cadmium is likely a potent inhibitor of most PPM family members except for PHLPPs. Furthermore, we demonstrated that cadmium inhibits PPM1A-regulated MAPK signaling and PPM1G-regulated AKT signaling potently in vivo. Cadmium reversed PPM1A-induced cell cycle arrest and cadmium insensitive PPM1A mutant rescued cadmium induced cell death. Taken together, these findings provide a better understanding of the effects of the toxicity of cadmium in the contexts of human physiology and pathology.

C admium, the 48th element in the periodic table of the elements, is a bluish-white, soft, malleable metal that was discovered in the early 19th century as a minor component of zinc ores. Since its discovery, cadmium has been used in red, orange, and yellow pigments and as a coating for alloys, a source of blue-ultraviolet laser light and a sensor of infrared light. Currently, most cadmium is used in nickel-cadmium batteries, the consumption of which is approximately 20000 tons per year worldwide.

Cadmium has long been recognized as a hazardous material, and its use has been restricted in Europe since the 1980 s by the "REACH Regulation". Individuals in the USA ingest approximately $30 \mu \mathrm{g}$ of cadmium per day through eating or smoking, and people in Asian countries such as China or Japan consume considerably higher amounts ${ }^{1}$. In addition to daily consumption, cadmium exposure can result from the disposal of electronic components and uncontrolled mining operations. For example, cadmium pollution in the Jinzu River led to itai-itai disease and renal abnormalities ${ }^{2}$. Recently, the leakage of cadmium in the Guangxi region has been reported in $\mathrm{China}^{3}$. Human exposure to cadmium can lead to hypertension, cancer, organ dysfunction, and immune system disorders. After an acute exposure, the half-life of cadmium in the human body is approximately 20-30 years ${ }^{4-6}$. Cadmium has no known physiological role in higher organisms, although it can substitute for zinc in carbonic anhydrases in marine diatoms living in habitats with very low zinc concentrations?

The mechanism leading to cadmium toxicity is complicated, and multiple cellular targets have been reported. For example, cadmium inhibit the functions of zinc finger proteins ${ }^{8}$, regulate intracellular calcium ${ }^{9-12}$, alter ROS signaling and inhibit DNA repair ${ }^{13}$. In addition, it has been shown that cadmium exposure affects phosphorylation cascades. Specifically, all three major MAPK signaling pathways-ERK, P38 and JNK—can be activated by cadmium in different cellular contexts ${ }^{14-17}$; however, the mechanism remains elusive. In cells, protein phosphorylation is precisely regulated by the concerted actions of protein kinases and protein phosphatases ${ }^{18-20}$. Although 
long-term exposure to cadmium has been shown to decrease the protein levels of PP5 and PP2A-A subunit ${ }^{21}$, it has not been investigated whether cadmium can regulate protein phosphorylation by directly binding to kinases or phosphatases. A better understanding of cadmium's function in biological systems, including the interaction between cadmium and phosphatases, is of great importance in treating cadmium exposure-related toxicity.

The human protein phosphatase superfamily includes approximately 100 tyrosine phosphatases and 40 Ser/Thr phosphatases. Unlike protein tyrosine phosphatases, which generally utilize an intrinsic residue, such as Cys or Asp, as the nucleophile to attack the phosphate group, many Ser/Thr phosphatases require a metal ion to activate a water molecule to carry out the dephosphorylation reaction ${ }^{19}$. Divalent metal ions bind to members of the PPM Ser/ Thr phosphatase family and act as either activators or inhibitors ${ }^{22}$. As a prototype of the PPM family, PPM1A was identified to be activated by $\mathrm{Mn}^{2+}$ ions but inhibited by $\mathrm{Ca}^{2+23}$. In the present study, we further investigated how metal ions affect catalysis by PPM family phosphatases. We found that the VIIb-2B metal ion cadmium is a potent inhibitor of PPM1A and PPM1G, with a $\mathrm{K}_{\mathrm{i}}$ of approximately $1 \mu \mathrm{M}$. In addition, the specificity and molecular mechanism of the cadmium-mediated inhibition of PPM family phosphatases was investigated in vitro and in cells.

\section{Results}

Profiles of the effects of metal ions on the activities of PPM1 A and PPM1G. The PPM family phosphatases are a large group of $\mathrm{Mg}^{2+}$ - or $\mathrm{Mn}^{2+}$-dependent Ser/Thr phosphatases that regulate important cellular functions, with at least 17 members in Homo sapiens. All members of the PPM family examined to date require metal ions for their phosphatase activity due to the essential role of the metals in bridging the active site residues of the enzyme to the nucleophilic water and in reducing the $\mathrm{pK}_{\mathrm{a}}$ of the water's oxygen to promote efficient catalysis ${ }^{22}$. Although some divalent metal ions, such as $\mathrm{Mn}^{2+}, \mathrm{Mg}^{2+}, \mathrm{Fe}^{2+}$ and $\mathrm{Co}^{2+}$, have been shown to efficiently activate several PPM family phosphatases, other divalent ions, such as $\mathrm{Ca}^{2+}$ and $\mathrm{Zn}^{2+}$, are inhibitors of these phosphatases ${ }^{23}$. To broaden the knowledge of the effects of metal ions on PPM family phosphatases, we examined more metal ions in phosphatase assays to determine their abilities to activate two PPM family phosphatase members, namely, PPM1A and PPM1G. $\mathrm{Mg}^{2+}, \mathrm{Mn}^{2+}, \mathrm{Fe}^{2+}, \mathrm{Co}^{2+}$, and $\mathrm{Ni}^{2+}$ activated both PPM1A and PPM1G, whereas other metal ions exhibited no detectable or only weak activity (Fig. 1a). The metal ions with low/no activity might be phosphatase inhibitors that competitively occupy the active center and prevent the binding of active metals. Therefore, we next examined the inhibition constants of these metal ions. The rankings of the inhibition potencies of these metal ions for the two tested phosphatases were very similar: $\mathrm{Cd}^{2+}>$ $\mathrm{Zn}^{2+}>\mathrm{Hg}^{2+}>\mathrm{Ca}^{2+}>\mathrm{Sr}^{2+}>\left(\mathrm{Cr}^{2+}, \mathrm{Ba}^{2+}\right)>\mathrm{Li}^{+}$(Fig. $1 \mathrm{~b}$ and $\mathrm{c}$ )

Interestingly, we noticed that metal ions in groups IIA and IIB of the periodic table, except for $\mathrm{Mg}^{2+}$, hardly activate PPM1A and PPM1G (Supplemental Fig. S1). These inactive metals all have completely filled s or d sub-orbitals (Fig. 1b, 1c and Supplemental Fig. S1). Conversely, most PPM1A or PPM1G activators are transition metals that have unfilled $d$ sub-orbitals (Fig. 1a and Supplemental Fig. S1). These observations suggest that the energy and properties of the outer sub-orbital electrons of a metal ion are important for that metal's ability to activate PPM phosphatases, most likely through increasing the negative charge of the water coordinated by these ions, to promote the efficient nucleophilic attack of the phosphorous atom of the substrate via an $\mathrm{S}_{\mathrm{N}} 2$ mechanism (Supplemental Fig. S2). Thus, we calculated the atomic net charges of the oxygen atom $\left(\mathrm{O}^{*}\right)$ interacting with different metal ions using the semi-empirical PM6 method $^{24}$. The computational results agree well with the activity profiles of the metal ions obtained from the phosphatase assay (Supplemental Table S1).
Cadmium is a potent and competitive inhibitor of PPM1A and PPM1G. Among the 8 inhibitory metal ions screened, cadmium unexpectedly potently inhibited both PPM1A and PPM1G, with a $\mathrm{K}_{\mathrm{i}}$ below $1 \mu \mathrm{M}$, which is approximately 1 order of magnitude better than the $\mathrm{K}_{\mathrm{i}}$ of $\mathrm{Zn}^{2+}$, the second most potent inhibitor in this series of metals (Fig. 1b and 1c). To determine the inhibition mode of $\mathrm{Cd}^{2+}$ for PPM1A and PPM1G, the effects of $\mathrm{Cd}^{2+}$ on the phosphatase hydrolysis reaction were examined using 7 different $\mathrm{Mn}^{2+}$ concentrations and 4 different $\mathrm{Cd}^{2+}$ concentrations. The $\mathrm{Mn}^{2+}$-dependent PPM1A- and PPM1G-catalyzed pNPP hydrolysis reactions inhibited by $\mathrm{Cd}^{2+}$ displayed the typical intersecting line pattern for competitive inhibition, with $\mathrm{K}_{\mathrm{i}}$ values of $300 \mathrm{nM}$ and $170 \mathrm{nM}$, respectively (Fig. 1d and 1e). The observed competitive mode of inhibition of $\mathrm{Mn}^{2+}$-dependent PPM phosphatase activity by $\mathrm{Cd}^{2+}$ suggests that $\mathrm{Cd}^{2+}$ and $\mathrm{Mn}^{2+}$ bind in a mutually exclusive manner to the same site in the phosphatase active center.

Cadmium exhibits 3 orders of magnitude better selectivity for the inhibition of PPM over PP1. Catalysis by phosphoprotein phosphatases (PPPs) also involves a central role of metal ions. By forming functional complexes with their regulatory subunits, 7 human PPP family members have diverse phospho-protein substrates and regulate many cellular processes ${ }^{25}$. To explore the specificity of cadmium inhibition, we next examined the effects of metal ions on catalysis by PP1, the prototype PPP family member.

We first looked into the activation of PP1 by different metal ions. The metal ion concentration-dependent PP1 catalysis obeyed the Michaelis-Menten saturation kinetics. Therefore, we analyzed the metal ion-dependent PP1 activation by treating these metal ions as pseudo-substrates (Fig. 2a and 2b). Similar to their effects on PPM1A and PPM1G, $\mathrm{Mn}^{2+}, \mathrm{Mg}^{2+}, \mathrm{Fe}^{2+}, \mathrm{Co}^{2+}$ or $\mathrm{Ni}^{2+}$ were all activators of $\mathrm{PP} 1$, with $\mathrm{k}_{\text {cat }}$ values ranging from 0.05 to $10 \mathrm{~S}^{-1}$ (Fig. 2b). We next examined the inhibitory effects of metal ions on PP1. $\mathrm{Zn}^{2+}, \mathrm{Cd}^{2+}$, and $\mathrm{Hg}^{2+}$ were PP1 inhibitors, with $\mathrm{K}_{\mathrm{i}}$ values ranging from $100 \mu \mathrm{M}$ to $1 \mathrm{mM}$ (Fig. 2c). The inhibitory constant of $\mathrm{Cd}^{2+}$ for PP1 was 3 orders of magnitude higher than the $\mathrm{K}_{\mathrm{i}}$ for PPM1A or PPM1G (Fig. $2 \mathrm{c}$ and 2d). Similar to PP1, the $\mathrm{IC}_{50}$ of $\mathrm{Cd}^{2+}$ toward another PPP family member, PP2A, was $130 \mu \mathrm{M}$ (Supplemental Fig. S3). Therefore, cadmium is a selective inhibitor of PPM1A and PPM1G over the PPP family phosphatase PP1 and PP2A.

Cadmium inhibits PPM1A and PPM1G through the M1 metal binding site. In the canonical binuclear metal center of PPM Ser/ Thr phosphatases, each metal ion is hexa-coordinated by invariant active site residues and waters ${ }^{22}$. The competitive mode of inhibition of $\mathrm{Mn}^{2+}$-dependent PPM phosphatase activity by $\mathrm{Cd}^{2+}$ suggests that $\mathrm{Cd}^{2+}$ inhibits PPM phosphatase activity through at least one of the two $\mathrm{Mn}^{2+}$ binding sites identified by previous crystallographic studies $^{22,26}$. To probe the underlying mechanism by which $\mathrm{Cd}^{2+}$ inhibits PPM phosphatases, 27 site-directed mutants targeting 9 conserved active site residues were created to test the effects of these mutations on the inhibitory effect of $\mathrm{Cd}^{2+}$ (Fig. 3a, 3b and Table 1). The 8 conserved active site residues are grouped into 3 categories $\left.^{27}: 1\right)$ residues not directly coordinated with the metal ions but essential for catalysis (R33 and H62 in PPM1A and R36 and $\mathrm{H} 62$ in PPM1G); 2) residues coordinated with the M1 metal ion binding site (D60, D239 and D282 in PPM1A and D60, D441 and D496 in PPM1G); 3) residues coordinated with the M2 metal ion binding site directly or through a water (E37, D38, D60 and G61 in PPM1A and E40, D41, D60 and G61 in PPM1G) (Fig. 3c and 3d).

The guanine group of PPM1A R33 was shown to mediate the phosphate-enzyme interactions in the original PPM1A crystal structure $^{22}$. We firstly examined the mutating effect of R33 on the intrinsic phosphatase activity. Removing the guanine group in PPM1A (R33A) or PPM1G (R36A) increased the $\mathrm{K}_{\mathrm{m}}$ for $\mathrm{pNPP}$ by 2- and 7-fold, respectively (Supplemental Table S2). The results were consistent with the previous crystal structure, which revealed that the 


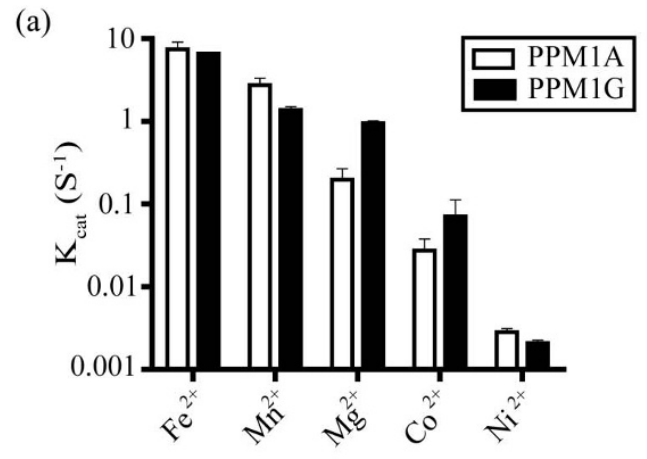

(b)

(d)

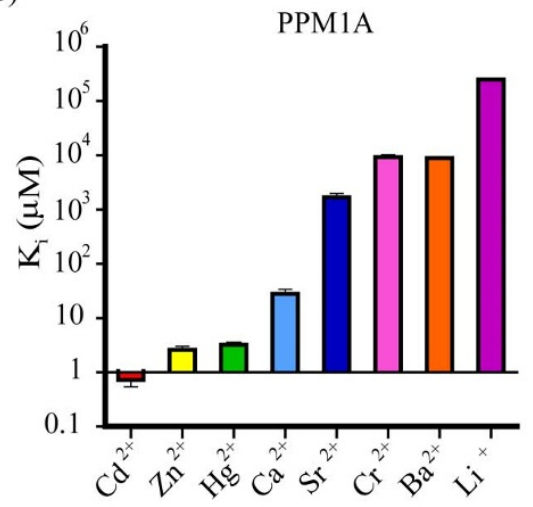

PPM1A

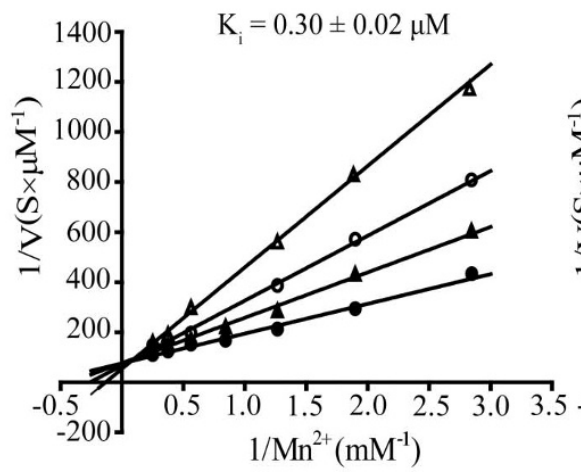

(c)

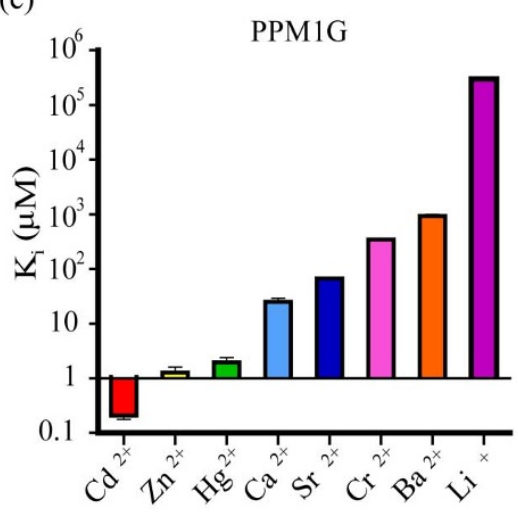

(e)

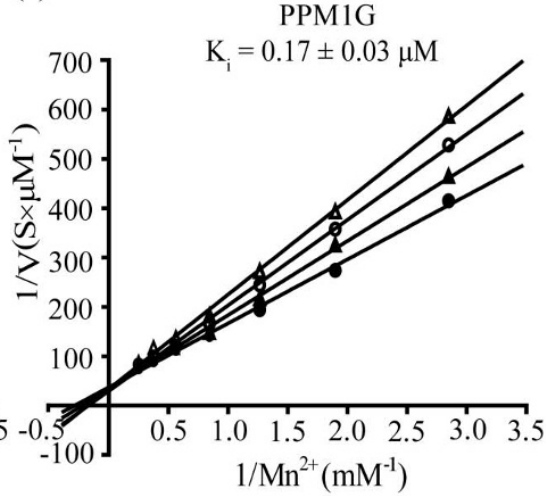

Figure $1 \mid$ Profiles of the effects of metal ions on the phosphatase activities of PPM1A and PPM1G, for which cadmium is a potent and competitive inhibitor. (a) $\mathrm{k}_{\text {cat }}$ of the metal ion-dependent phosphatase activities of PPM1A and PPM1G. All assays were conducted in Tris/Bis-Tris/acetate buffer at $\mathrm{pH} 8.0$ and $25^{\circ} \mathrm{C}$. (b-c) Inhibition of PPM1A- and PPM1G-catalyzed pNPP hydrolysis by different divalent metals ions. Colors: $\mathrm{Cd}^{2+}(\mathrm{red}), \mathrm{Zn}^{2+}$ (yellow), $\mathrm{Hg}^{2+}$ (green), $\mathrm{Ca}^{2+}$ (light blue), $\mathrm{Sr}^{2+}$ (dark blue), $\mathrm{Cr}^{2+}$ (pink), $\mathrm{Ba}^{2+}$ (orange), and $\mathrm{Li}^{+}$(purple). (d-e) Double-reciprocal plot (1/V vs. $1 /\left[\mathrm{Mn}^{2+}\right]$ ) of the effect of $\mathrm{Cd}^{2+}$ on PPM1A/PPM1G-catalyzed pNPP hydrolysis. $\mathrm{Mn}^{2+}$ was the variable substrate, and $\mathrm{Cd}^{2+}$ was the inhibitor $(\bullet 0, \mathbf{\Delta} 0.25, \bigcirc 0.5$, $\triangle 1.0 \mu \mathrm{M})$. The pNPP concentration was held constant at $20 \mathrm{mM} . \mathrm{K}_{\mathrm{i}}(\mathrm{PPM} 1 \mathrm{~A})=0.30 \pm 0.02 \mu \mathrm{M} . \mathrm{K}_{\mathrm{i}}(\mathrm{PPM} 1 \mathrm{G})=0.17 \pm 0.03 \mu \mathrm{M}$.

guanine group of this arginine forms a salt bridge with the phosphate group. The R to A mutation in PPM1A and PPM1G also decreased the $\mathrm{k}_{\text {cat }}$ slightly but did not change the $\mathrm{K}_{\text {metal }}$ for $\mathrm{Mn}^{2+}$, suggesting that these mutations did not disrupt the overall structures of the phosphatases (Table 1 and Supplemental Table S2). We next examined the effects of these mutations on $\mathrm{Cd}^{2+}$ inhibition. No significant effects on $\mathrm{K}_{\mathrm{i}}$ were observed (Table 1).

Although the above experimental results indicate that R33 of PPM1A is important for efficient substrate hydrolysis, R33 is not a well-conserved residue among PPM phosphatases. Among the 17 PPM phosphatase members, 5 members have a lysine and 2 others have an asparagine at corresponding residue 33 of PPM1A (Fig. 3e). Therefore, we assessed the catalytic activity and $\mathrm{Cd}^{2+}$ binding for the R33K and R33N mutants of PPM1A. Similar to the R33A mutant of PPM1A, the R33K and R33N mutants of PPM1A exhibited decreased phosphatase activity as the result of both a higher $\mathrm{K}_{\mathrm{m}}$ and a lower $\mathrm{k}_{\text {cat }}$ (Supplemental Table S1), but these mutations had little effect on $\mathrm{Mn}^{2+}$ binding or $\mathrm{Cd}^{2+}$ inhibition (Table 1).

We then tested mutations of H62, which has been suggested to behave as the general acid in the cleavage of the P-O bond during catalysis $^{27}$. Both H62A and H62N decreased the PPM1G phosphatase activity by approximately 6 -fold by reducing the $\mathrm{k}_{\mathrm{cat}}$ but had no effects on $\mathrm{K}_{\mathrm{m}}$, in good agreement with the major role of this residue in product conversion (Supplemental Table S2). The H62 mutations had little effect on $\mathrm{Mn}^{2+}$ binding or $\mathrm{Cd}^{2+}$ inhibition (Fig. 3a and 3b). Taken together, these results demonstrate that the conserved catalytic residues that are not part of the metal binding sites, such as R33 and H62 in the PPM1A, are important for phosphatase activity but do not participate in $\mathrm{Cd}^{2+}$ binding.

In the metal ion binding sites of PPM1A, the two metal ions are 4 $\AA$ apart and are bridged by the combination of a nucleophilic water and the conserved catalytic residue Asp60 (Fig. $3 \mathrm{c}$ and $3 \mathrm{~d}$ ) ${ }^{22}$. The 
(a)

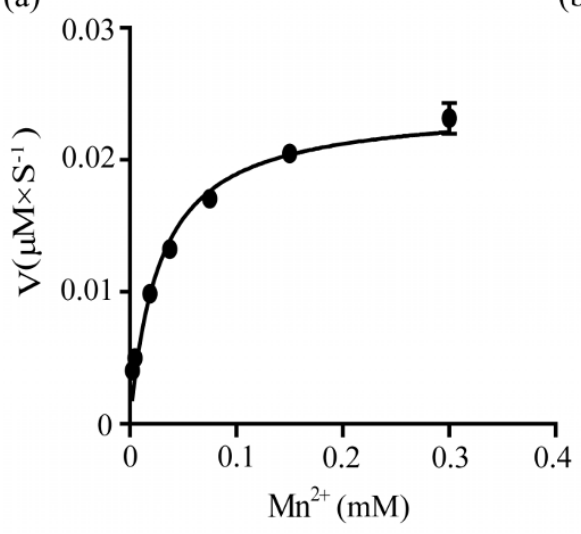

(b)

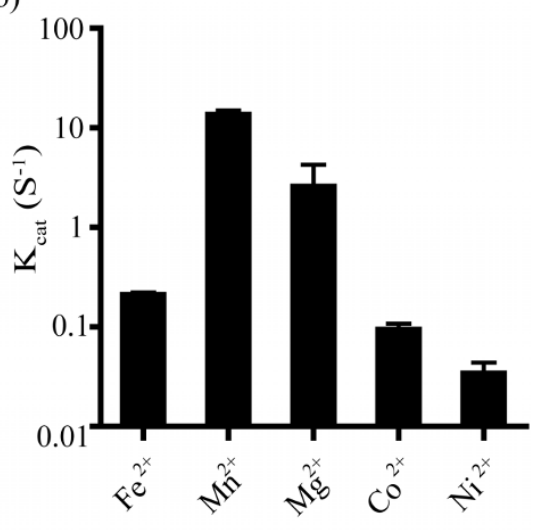

(c)

\begin{tabular}{lc}
\hline & $\mathrm{K}_{\mathrm{i}}(\mu \mathrm{M})$ \\
\hline $\mathrm{Cd}^{2+}$ & $120 \pm 20$ \\
$\mathrm{Zn}^{2+}$ & $284 \pm 29$ \\
$\mathrm{Hg}^{2+}$ & $490 \pm 51$ \\
$\mathrm{Ca}^{2+}>1000$ \\
$\mathrm{Sr}^{2+}>1000$ \\
$\mathrm{Cr}^{2+}>1000$ \\
$\mathrm{Ba}^{2+}>1000$ \\
$\mathrm{Li}^{+}>1000$ \\
\hline
\end{tabular}

(d)

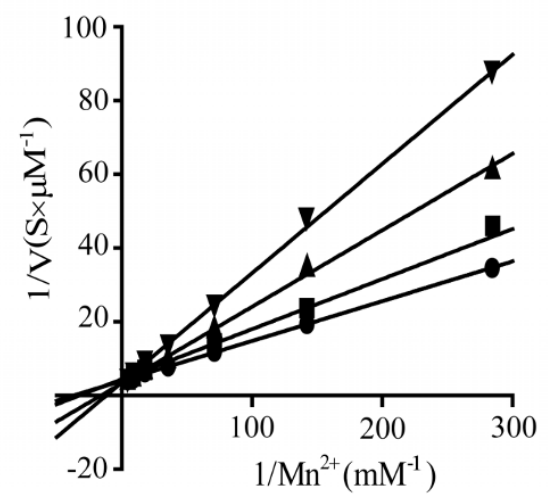

Figure $2 \mid$ Kinetic analysis of the effects of metals on PP1. (a) $\mathrm{Mn}^{2+}$ concentration-dependent activation of the PP1 phosphatase. The Mn ${ }^{2+}$ concentration was varied in the presence of saturating levels of pNPP. The rates (V) were determined by measuring the pNP concentration at $405 \mathrm{~nm}$. The data were fitted to the Michaelis-Menten equation. The assays were performed in Tris/Bis-Tris/acetate buffer, $\mathrm{pH} 8.0,25^{\circ} \mathrm{C}$. (b) $\mathrm{k}_{\mathrm{cat}}$ of the metal iondependent activity of PP1. (c) $\mathrm{K}_{\mathrm{i}}$ values for the inhibition of PP1-catalyzed pNPP hydrolysis by different divalent metal ions. (Metals with $\mathrm{K}_{\mathrm{i}}>1 \mathrm{mM}$ were not determined). (d) Double-reciprocal plot $\left(1 / \mathrm{V}\right.$ vs. $\left.1 /\left[\mathrm{Mn}^{2+}\right]\right)$ showing the effects of $\mathrm{Cd}^{2+}$ on PP1-catalyzed pNPP hydrolysis. Cd ${ }^{2+}$ was the inhibitor, and $\mathrm{Mn}^{2+}$ was the variable substrate $(\bullet 100, \boldsymbol{\square} 200, \boldsymbol{\Delta} 300, \boldsymbol{\nabla} 400 \mu \mathrm{M})$. The concentration of pNPP was held at $20 \mathrm{mM} . \mathrm{K}_{\mathrm{i}}(\mathrm{PP} 1)=120 \pm 20 \mu \mathrm{M}$.

D60A and D60N mutations in both PPM1A and PPM1G significantly reduced the phosphatase activities of these proteins but had subtle effects on the $\mathrm{K}_{\mathrm{m}}$ for pNPP (Supplemental Table S2). The mutation of D60 may perturb the metal ion center, changing the negative charge of the nucleophilic water and reducing its $\mathrm{k}_{\text {cat }}$. Conversely, the small effect of D60 on the $\mathrm{K}_{\mathrm{m}}$ for $\mathrm{pNPP}$ indicates that this residue does not affect the binding of the small substrate or the overall protein structure. Consistent with the position of D60 in the active site, the D60A and D60N mutations decreased both $\mathrm{Mn}^{2+}$ binding and the inhibitory potency of $\mathrm{Cd}^{2+}$ by 1 to 2 orders of magnitude (Table 1). Compared with the D60A mutant, the D60N mutant has an oxygen atom replaced by a nitrogen atom, which decreases the negative charge of the residue but retains its polar nature (Fig. 3c and 3d). The significant impairment of $\mathrm{Cd}^{2+}$ mediated inhibition by both D60A and D60N demonstrates that both the side chain and the negative charge of D60 are required for $\mathrm{Cd}^{2+}$ coordination.

In addition to D60, D239 and D282 in PPM1A (D441 and D496 in PPM1G) directly coordinate metal M1 (Fig. 3c and 3d). The D239A, D239K, and D282A mutations in PPM1A, together with the D441A, D441N, D496A, and D496N mutations in PPM1G, had little effect on the $K_{m}$ for pNPP but reduced the $k_{\text {cat }}$ by 100 - to 1000 -fold (Supplemental Table S2). Therefore, the residues coordinated to the metal in the M1 metal site are required for efficient catalysis but are not essential for substrate binding.

We then investigated the effects of these mutations on $\mathrm{Mn}^{2+}$ binding and $\mathrm{Cd}^{2+}$ inhibition. The elimination of the side chains of these aspartic residues resulted in the loss of $\mathrm{Cd}^{2+}$-mediated inhibition by more than one order of magnitude (Fig. $3 \mathrm{a}$ and $3 \mathrm{~b}$ ). To only reduce the negative charge of these conserved residues, the aspartic acid was substituted with lysine or asparagine. The inhibitory activities of $\mathrm{Cd}^{2+}$ on the D239K mutant of PPM1A and the D441N and D496N mutants of PPM1G were reduced by more than 45 -fold (Table 1 and Fig. 3). Although most of the mutations also affected $\mathrm{Mn}^{2+}$ binding, the $\mathrm{K}_{\mathrm{m}}$ for $\mathrm{Mn}^{2+}$ of the PPM1G D441N mutant was not significantly different from that of the wild-type enzyme (Table 1). The D441N mutation only reduced the negative charge of the residue and retained its polar nature. This result suggests the possibility that the negatively charged D441 residue in PPM1G has a role in recognizing cadmium over other metal ions. We then measured the inhibitory effects of different metal ions on the D441N mutant of PPM1G, and we compared the $\mathrm{IC}_{50}$ values with those of the wild-type enzyme. The D441N mutation decreased the levels of inhibition by $\mathrm{Cd}^{2+}, \mathrm{Zn}^{2+}, \mathrm{Ca}^{2+}$ and $\mathrm{Sr}^{2+}$ by more than 10 -fold but increased the levels of inhibition by $\mathrm{Hg}^{2+}, \mathrm{Cr}^{2+}$ and $\mathrm{Li}^{+}$by between 2 and 7 -fold (Fig. $3 \mathrm{f}$ and $3 \mathrm{~g}$ ). Therefore, the above results indicate that the unique properties of the M1 metal ion binding site contribute to the inhibitory activities of $\mathrm{Cd}^{2+}$. In particular, the negative charge of D441 imparts selectivity for coordinating $\mathrm{Cd}^{2+}, \mathrm{Zn}^{2+}, \mathrm{Ca}^{2+}$ and $\mathrm{Sr}^{2+}$ but is not required for binding to several other metal ions, such as $\mathrm{Mn}^{2+}, \mathrm{Hg}^{2+}$ and $\mathrm{Cr}^{2+}$.

Next, we examined the effects of mutations in the M2 metal ion binding site on the inhibitory activity of $\mathrm{Cd}^{2+}$. The $\mathrm{M} 2$ metal ion is coordinated by a nucleophilic water, D60, the carbonyl oxygen from 

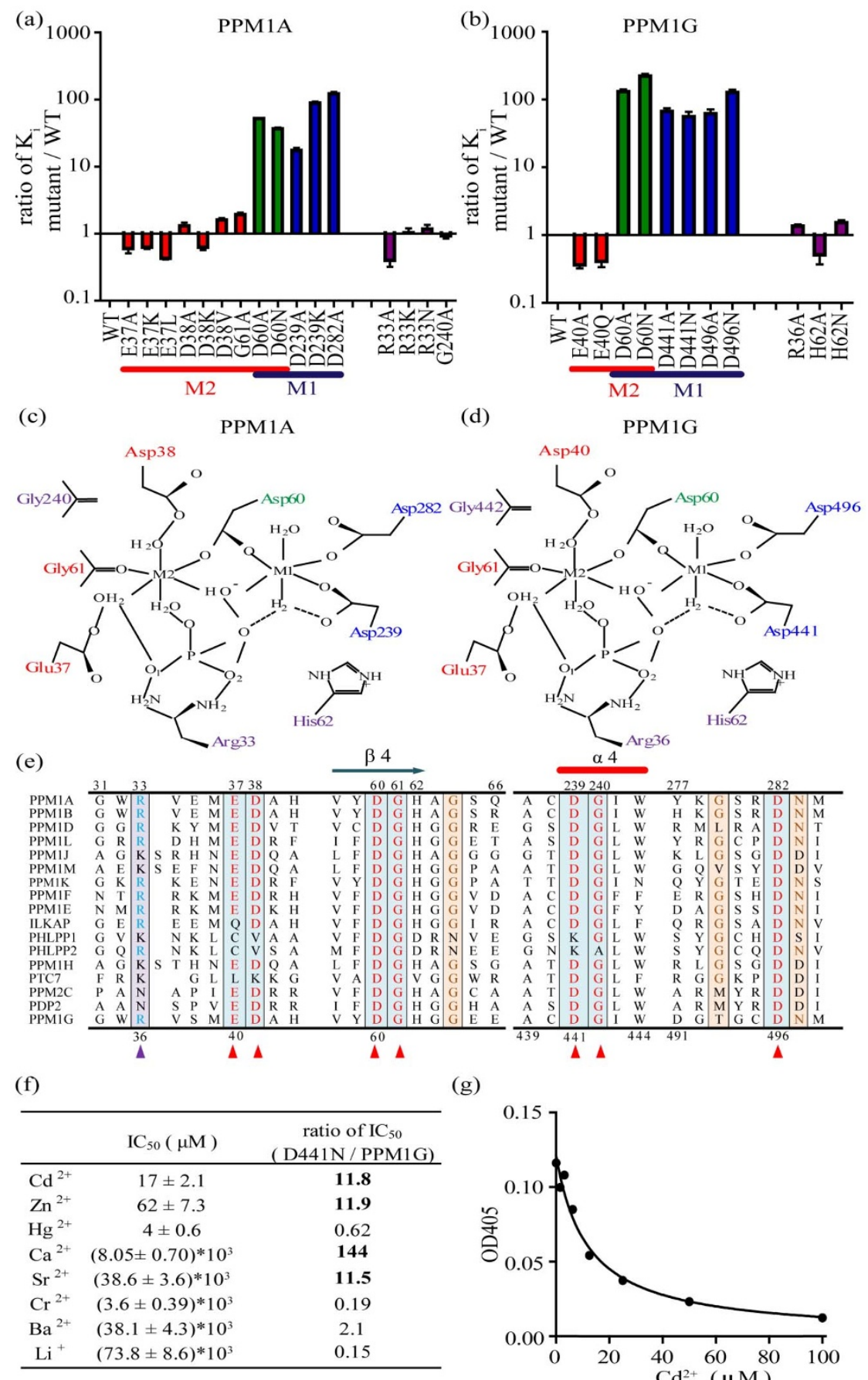

(e)

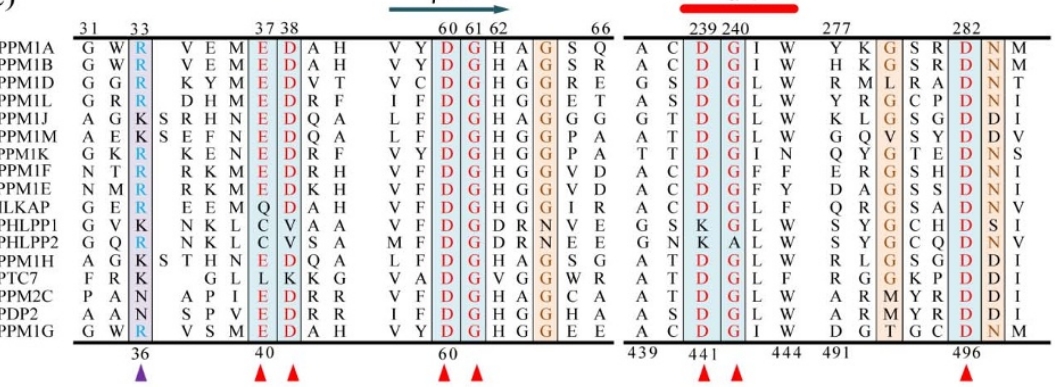

(g)

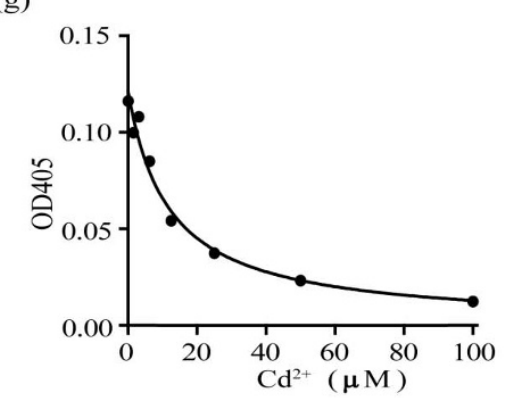

Figure $3 \mid$ Cadmium inhibits PPM1A and PPM1G through the M1 metal ion binding site. (a-b) Column graph of the $\mathrm{K}_{\mathrm{i}}$ values of $\mathrm{Cd}^{2+}$ for the wild-type enzymes and the PPM1A and PPM1G mutants. All assays were performed in Tris/Bis-Tris/acetate buffer with $\mathrm{Mn}^{2+}$ as the variable substrate at saturating levels of pNPP. Colors: Residues that exclusively coordinate with the M2 metal binding site are red, residues that exclusively coordinate with the M1 metal binding site are blue, and residues shared by the M1 and M2 sites are green. Residues not associated with the metal ion centers are purple. (c-d) Schematic representation of the active center of human PPM1A and PPM1G based on the X-ray crystal structure reported by Das et a ${ }^{22}$. (e) Multiple amino acid sequence alignment of human PPM1A and PPM1G with the signature sequence motifs of all other members of the PPM family in humans. The amino acids of PPM1A and PPM1G are numbered on the top and bottom, respectively. The residues that bind to the metal ions or phosphate ions are shown in red and blue, respectively. (f) $\mathrm{IC}_{50}$ values of different divalent metal ions for the inhibition of the PPM1G D441N mutant and their relative ratio compared with wild-type PPM1G. (g) Concentration-dependent inhibition of D441N activity on pNPP by $\mathrm{Cd}^{2+}$.

G61 and three waters that interact with the phosphate oxygen, E37 and D38 of PPM1A (E40 and D41 of PPM1G) (Fig. 3c and 3d).

In the crystal structure of PPM1A, the side-chain oxygen of E37 participates in a water-mediated $\mathrm{H}$-bond network with either the M2 metal ion or the oxygen of the phosphate (Fig. 3c and 3d). The E37A mutation in PPM1A or in PPM1G decreased the $\mathrm{k}_{\mathrm{cat}}$ by 2 -3-fold but had little effect on the $\mathrm{K}_{\mathrm{m}}$ (Supplemental Table S2). We also examined the effects of the E37C and E37L mutations in PPM1A and the E40Q mutation in PPM1G to mimic other PPM phosphatases (Fig. 3e). Similar to what was observed for the E37A mutation, the change in polarity caused by the E37C and E37L mutations in PPM1A decreased the $\mathrm{k}_{\mathrm{cat}}$ but had little effect on the $\mathrm{K}_{\mathrm{m}}$. The 


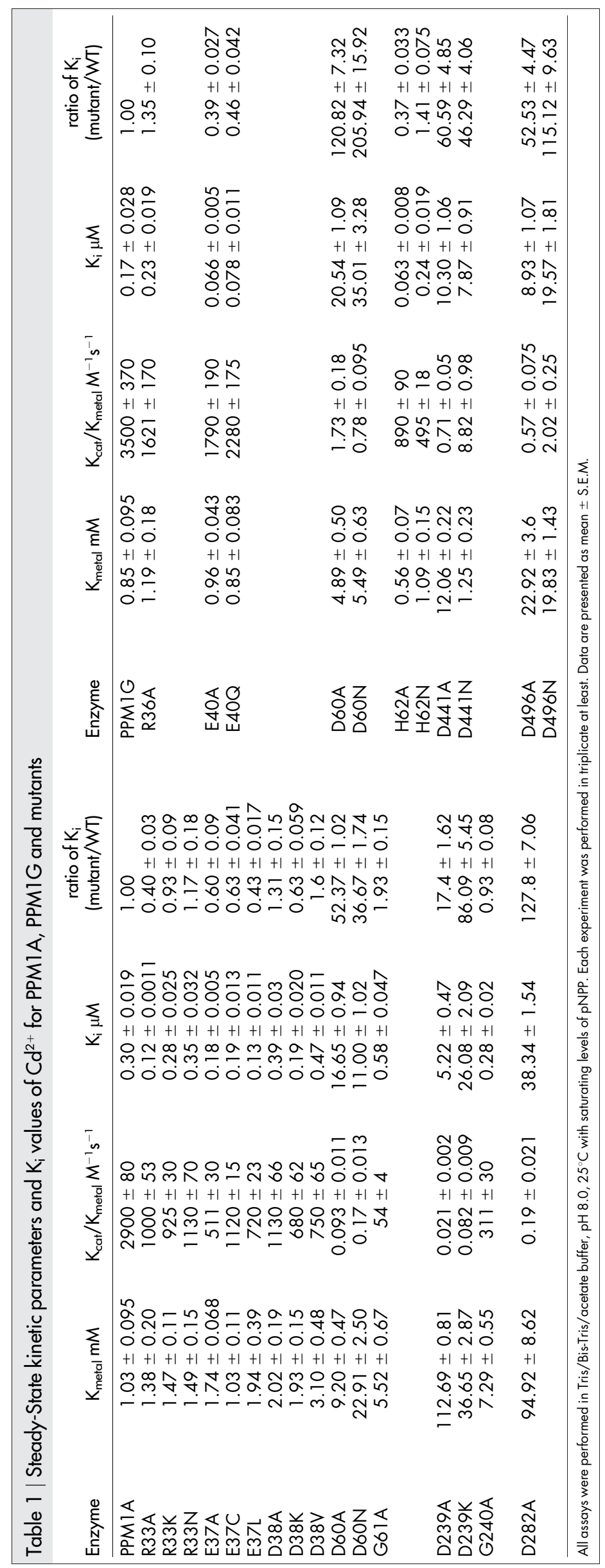


(a)

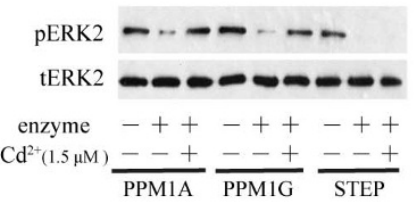

(e)

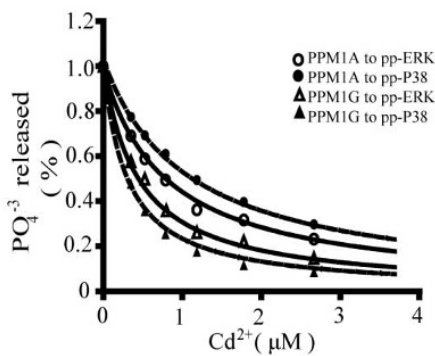

(b)

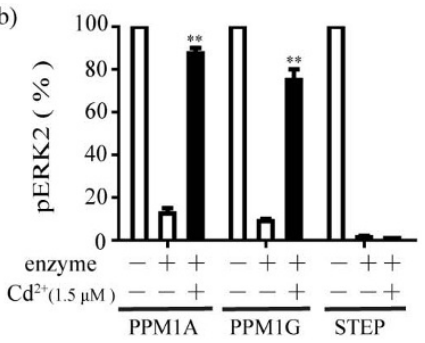

(f)

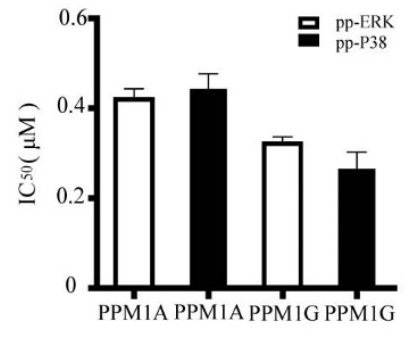

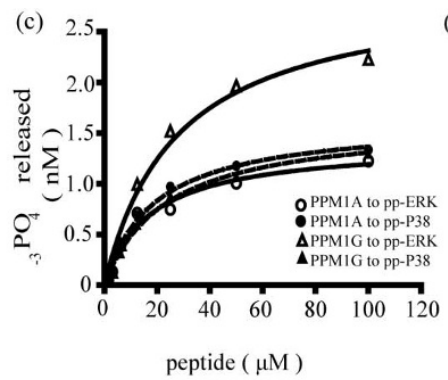

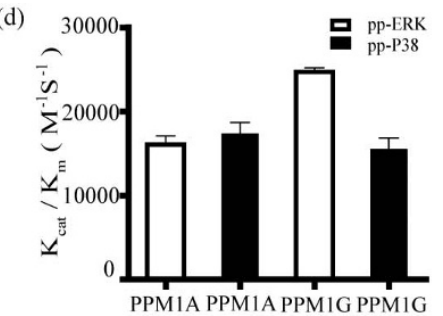

(g)

(h)

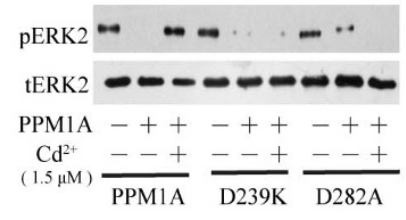

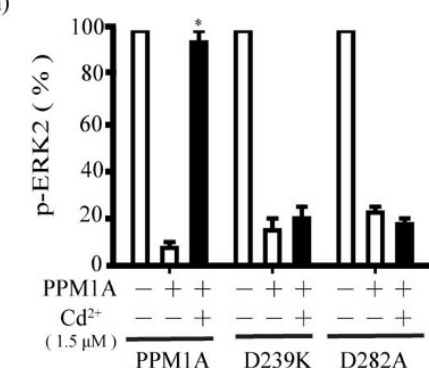

Figure $4 \mid$ Cadmium selectively inhibits the hydrolysis of protein and peptide substrates by PPM1A and PPM1G. (a) Cadmium affects the dephosphorylation of pp-ERK2 by the tyrosine phosphatase STEP and phosphatases of the PPM family, PPM1A and PPM1G in vitro. The assays were performed in Tris/Bis-Tris/acetate buffer at $\mathrm{pH} 8.0$ and $37^{\circ} \mathrm{C}$ with $1.5 \mu \mathrm{M} \mathrm{Cd}^{2+}$ and $1 \mathrm{mM} \mathrm{Mn}^{2+}$. The reactions were initiated by adding the phosphatases. The status of ERK phosphorylation was determined using a phospho-ERK antibody. (b) Statistical analysis of the dephosphorylation of pp-ERK2 by different phosphatases (Fig. 4a). All experiments were repeated in triplicate. ${ }^{*} \mathrm{P}<0.01$. (c) The enzyme-catalyzed hydrolysis of phospho-peptides derived from pp-ERK2 (TGFLpT ${ }^{202} \mathrm{EpY}^{204} \mathrm{VATR}$ ) and pp-P38 (TDDEMpT ${ }^{180} \mathrm{GpY} \mathrm{Y}^{182} \mathrm{VAT}$ ). $\bigcirc$ : PPM1A-catalyzed hydrolysis of ppERK2, $\triangle$ : PPM1Gcatalyzed hydrolysis of ppERK2, $\bullet$ : PPM1A-catalyzed hydrolysis of pp-P38, $\mathbf{\Delta}$ : PPM1G-catalyzed hydrolysis of pp-P38. (d) Column graph of the $\mathrm{k}_{\text {cat }} /$ $\mathrm{K}_{\mathrm{m}}$ values of PPM1A and PPM1G for the dephosphorylation of phospho-peptides derived from pp-ERK and pp-P38 (Fig. 4c). (e) Concentration dependence of the inhibition of PPM1A- and PPM1G-catalyzed hydrolysis of phospho-peptides by $\mathrm{Cd}^{2+}$. All labels are exactly the same as those in Fig. 4c. (f) Column graph of the $\mathrm{IC}_{50}$ values of $\mathrm{Cd}^{2+}$ for the dephosphorylation of pp-ERK and pp-P38 peptides by PPM1A and PPM1G, derived from the data in Fig. 4e. (g) Effects of $\mathrm{Cd}^{2+}$ on the dephosphorylation of the pp-ERK2 protein by wild-type PPM1A and its mutants (PPM1A D282A and PPM1A D239K) in vitro. (h) Statistical analysis of the dephosphorylation of pp-ERK2 by PPM1A and its mutants (Fig. 4g). All experiments were repeated in triplicate. $* * \mathrm{P}<0.01$

PPM1G E40Q mutation slightly decreased both the $\mathrm{k}_{\text {cat }}$ and $\mathrm{K}_{\mathrm{m}}$ but had no effect on the overall $\mathrm{k}_{\mathrm{cat}} / \mathrm{K}_{\mathrm{m}}$ value. Taken together, these results indicate that the polarity of E37 (E40 in PPM1G) contributes to the catalytic efficiency.

We then analyzed the binding of metals to E37 mutants (E40 in PPM1G). The 5 tested E37 (E40 in PPM1G) mutations did not reduce the $\mathrm{K}_{\text {metal }}$ of $\mathrm{Mn}^{2+}$ but increased the binding of $\mathrm{Cd}^{2+}$ by approximately 2 -fold (Table 1). Therefore, E37 in the M2 metal ion site does not contribute to the binding of $\mathrm{Cd}^{2+}$.

D38 of PPM1A also forms a water-mediated $\mathrm{H}$-bond with the M2 metal ion (Fig. 3c). Three PPM phosphatases have $\mathrm{K}$ or $\mathrm{V}$ at the position corresponding to D38. The D38A and D38V mutation in PPM1A had slight effects on the $\mathrm{k}_{\mathrm{cat}}$ and increased the $\mathrm{K}_{\mathrm{m}}$ by between 1.5- and 2-fold. The D38 mutations might affect the $\mathrm{K}_{\mathrm{m}}$ of pNPP by perturbing the interaction between the metal ion and the phosphate. In addition to D38 and E37 in PPM1A, the carbonyl oxygen of G61 directly coordinates with the M2 metal ion (Fig. 3c). The G61A mutation decreased the $\mathrm{k}_{\mathrm{cat}}$ by 10 -fold and increased the $\mathrm{K}_{\mathrm{m}}$ by 2-fold for pNPP (Supplemental Table S1). The essential role of G61 in catalysis agrees well with its conserved nature among all PPM family members (Fig. 3e).

Interestingly, although the D38V and G61A mutations increased the $\mathrm{K}_{\text {metal }}$ of $\mathrm{Mn}^{2+}$ by 3 - and 5-fold, respectively, they had less drastic effects on $\mathrm{Cd}^{2+}$ inhibition (Table 1). These results indicate that the M2 metal ion binding site residues contribute to catalysis and $\mathrm{Mn}^{2+}$ binding but are not determinants of $\mathrm{Cd}^{2+}$ inhibition.

Taken together, the results of the mutagenesis and kinetic studies demonstrate that the inhibitory effect of $\mathrm{Cd}^{2+}$ on PPM family phosphatases are mediated through the unique effect of this ion on the M1 metal ion binding site, and one of the special cadmium-binding features is the negative charge of the conserved D441 residue of PPM1G (Fig. 3c and 3d).

Cadmium selectively inhibits the hydrolysis of protein and peptide substrates by PPM1A and PPM1G over the activity of other tyrosine phosphatases. The human genome encodes at least 140 protein phosphatases. In addition to the PPM and PPP phosphatase families, there are more than 100 human protein phosphatases that belong to the protein tyrosine phosphatase (PTP) superfamily. These enzymes utilize the active site Cys to nucleophilically attack the phosphorous atom of the substrate and do not require a metal ion for activation ${ }^{28}$. To further test the selectivity of $\mathrm{Cd}^{2+}$ for PPM family phosphatases over PTPs, we compared the inhibitory effects of $\mathrm{Cd}^{2+}$ on the PPM1A-, PPM1G- and striatum-enriched phosphatase (STEP)-catalyzed hydrolysis of purified dual-phosphorylated ERK (extracellular signal regulated kinase) protein, which has been shown to be a physiological substrate of both STEP and PPM1A in previous studies by us and by other ${ }^{29-32}$. This experiment showed that $1.5 \mu \mathrm{M} \mathrm{Cd}^{2+}$ substantially blocked the PPM1A- and PPM1Gcatalyzed dephosphorylation of phospho-ERK but had no effect on STEP (Fig. $4 \mathrm{a}$ and $4 \mathrm{~b}$ ). This result suggests that the inhibitory activity of $\mathrm{Cd}^{2+}$ is specific for the PPM family and that this metal is not an inhibitor of the Cys-based PTP superfamily.

Phosphorylated P38 (pp-P38) is also an established physiological substrate of PPM1A in response to stress stimulation ${ }^{33}$. Without purified pp-P38 available, we examined the phosphatase activities of PPM1A and PPM1G on phospho-peptides derived from pp-ERK (TGFLpT ${ }^{202} \mathrm{EpY}^{204} \mathrm{VATR}$ ) and pp-P38 (TDDEMpT ${ }^{180} \mathrm{GpY}^{182} \mathrm{VAT}$ ) 
(a)

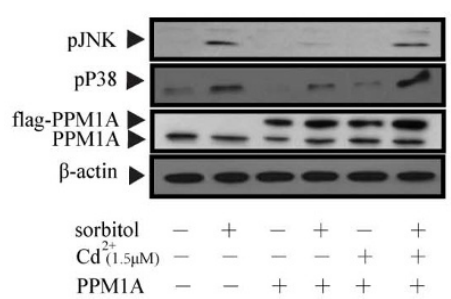

(d)

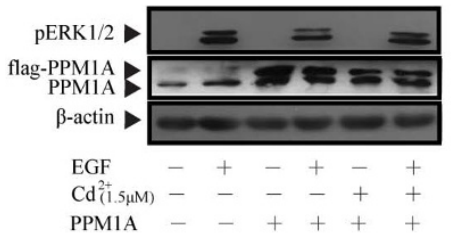

(h)

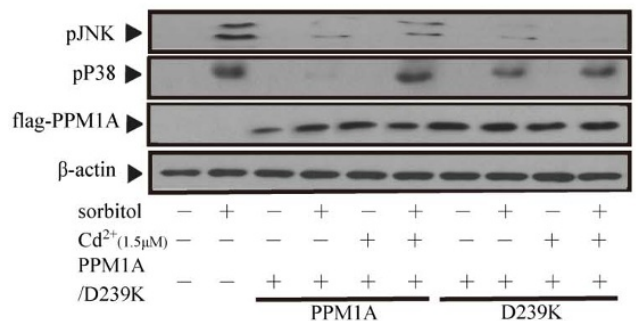

(b)

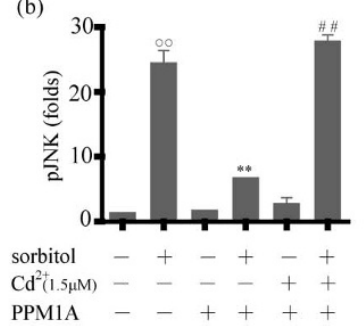

(e)

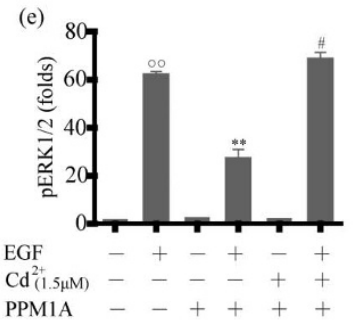

(i) (c)

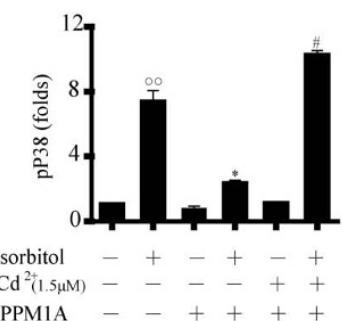

(f)

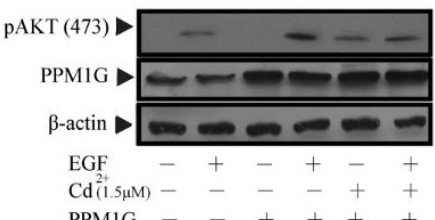

(g)

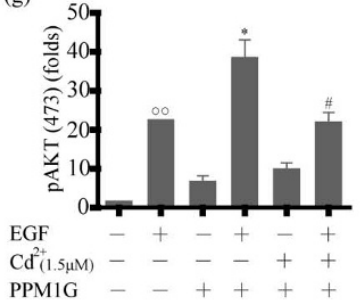

(j)

Figure 5 Cadmium suppresses PPM1A and PPM1G activity in cells. HEK293 cells were incubated in DMEM supplemented with 10\% FBS and transiently transfected with pcDNA3.1-flag-PPM1A or pcDNA3.1-flag-PPM1G. Sub-confluent HEK293 cells were serum-starved in DMEM for 12 h, incubated for $6 \mathrm{~h}$ with or without $1.5 \mu \mathrm{M} \mathrm{CdCl}_{2}$ and then treated with different stimulators. Cell lysate supernatants were prepared and analyzed by immunoblotting with specific antibodies. The data are from at least three experiments. $\bigcirc$ cells stimulated with EGF or sorbitol compared with unstimulated HEK293 cells; $\bigcirc: \mathrm{P}<0.05, \bigcirc \bigcirc: \mathrm{P}<0.01$. *: overexpression of PPM1A or PPM1G in HEK293 cells compared with control vectors; *: $<<$ 0.05 , **: $\mathrm{P}<0.01$. \#: Cells treated with $\mathrm{CdCl}_{2}$ compared with cells not treated with a metal ion; \#: $\mathrm{P}<0.05$,\#\#: $\mathrm{P}<0.01$. (a and $\mathrm{d}$ ) Cells were transfected with PPM1A or a control plasmid and then stimulated with sorbitol $\left(0.4 \mathrm{M}, 20 \mathrm{~min}, 37^{\circ} \mathrm{C}\right)$ or EGF $\left(5 \mathrm{ng} / \mathrm{ml}, 5 \mathrm{~min}, 37^{\circ} \mathrm{C}\right)$ after incubation with or without $1.5 \mu \mathrm{M} \mathrm{CdCl}_{2}$. The levels of phosphorylated JNK, P38, and ERK were monitored by immunoblotting with specific antibodies. Actin was used as a loading control. (b, c and e) Statistical analysis of the data presented in panels a and d. (f) Cells were transfected with wild-type PPM1G and stimulated with 5 ng/ $\mathrm{ml} \mathrm{EGF} \mathrm{for} 5 \mathrm{~min}$ at $37^{\circ} \mathrm{C}$ after incubation with or without $1.5 \mu \mathrm{M} \mathrm{CdCl}_{2}$ for $6 \mathrm{~h}$. The level of phosphorylated AKT(473) was monitored by immunoblotting with specific antibodies. (g) Statistical analysis of the data in panel f. (h) Cells were transfected with the control, PPM1A, or PPM1A D239K plasmid and then stimulated with sorbitol $\left(0.4 \mathrm{M}, 20 \mathrm{~min}, 37^{\circ} \mathrm{C}\right)$ after incubation with or without $1.5 \mu \mathrm{M} \mathrm{CdCl}_{2}$. The levels of phosphorylated JNK, P38 were monitored. (i and j) Statistical analysis of the data in panel h.

(Fig. 4c and 4d). PPM1A and PPM1G exhibited similar and reasonable phosphatase activities for the pp-ERK and pp-P38 phospho-peptides, with $\mathrm{k}_{\text {cat }} / \mathrm{K}_{\mathrm{m}}$ values ranging from 10000 to $30000 \mathrm{~S}^{-1}$. We then tested the inhibitory activity of $\mathrm{Cd}^{2+}$ on the PPM1A- and PPM1Gcatalyzed hydrolysis of these phospho-peptide substrates. The $\mathrm{IC}_{50}$ of $\mathrm{Cd}^{2+}$ for these phospho-peptide substrates was in the low micromolar range, similar to the values for the hydrolysis of the small artificial substrate pNPP (Fig. $4 \mathrm{e}$ and $4 \mathrm{f}$ ).

Kinetic and mutagenesis studies have revealed that $\mathrm{Cd}^{2+}$ inhibits PPM1A and PPM1G through the M1 metal binding site. Therefore, mutations in the M1 binding site might make these proteins less sensitive to $\mathrm{Cd}^{2+}$ inhibition. The $\mathrm{K}_{\mathrm{i}}$ values for the $\mathrm{D} 282 \mathrm{~A}$ and D239K mutants of PPM1A for pNPP were $128 \mu \mathrm{M}$ and $86 \mu \mathrm{M}$, respectively, indicating that the strength of the inhibition was approximately 2 orders of magnitude weaker than that of the wildtype enzyme (Table 1). To corroborate the lower sensitivity of these mutants to $\mathrm{Cd}^{2+}$ inhibition, we tested the inhibitory effects of $\mathrm{Cd}^{2+}$ on ERK dephosphorylation. Wild-type PPM1A efficiently dephosphorylated dual-phosphorylated ERK, and $1.5 \mu \mathrm{M} \mathrm{Cd}^{2+}$ blocked this activity (Fig $4 \mathrm{~g}$ and h). For the D282A and D239K mutants, the dephosphorylation was minimally affected by the addition of
$1.5 \mu \mathrm{M} \mathrm{Cd}^{2+}$ (Fig. 4g and 4h). Taken together, these results confirm that $\mathrm{Cd}^{2+}$ is an efficient inhibitor of phosphate removal from protein and peptide substrates by PPM family phosphatases and that M1 binding site mutants of PPM family phosphatases are insensitive to $\mathrm{Cd}^{2+}$ inhibition.

Cadmium suppresses PPM1A- and PPM1G-regulated signaling pathways in cells at a low micromolar concentration. Given the observed effects of $\mathrm{Cd}^{2+}$ on the phospho-peptide and protein substrates of PPM1A and PPM1G in vitro, we proceeded to evaluate the ability of $\mathrm{Cd}^{2+}$ to inhibit these two phosphatases inside cells. Previous studies have demonstrated that PPM1A negatively regulates osmotic stress signaling pathways by directly binding to and dephosphorylating phospho-P38 and phospho-JNK- $1^{33}$. Similar to previous observations, the overexpression of PPM1A by approximately 2-fold relative to the endogenous protein level in HEK293 cells significantly blocked sorbitol-induced P38 and JNK-1 phosphorylation. This result was drastically reversed by the application of a low micromolar concentration of $\mathrm{Cd}^{2+}$ (Fig. 5a, 5b and 5c).

Recently, our group and other researchers have reported that PPM1A negatively regulates NGF- and EGF-induced ERK 


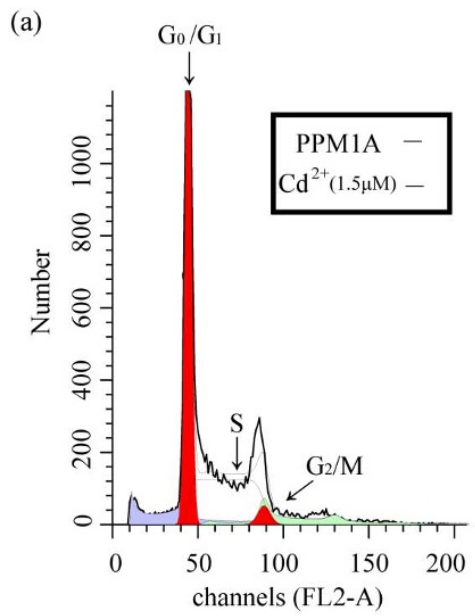

(b)

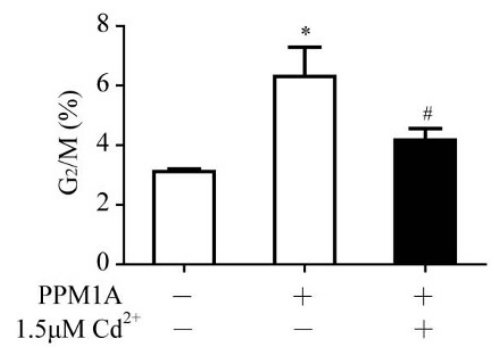

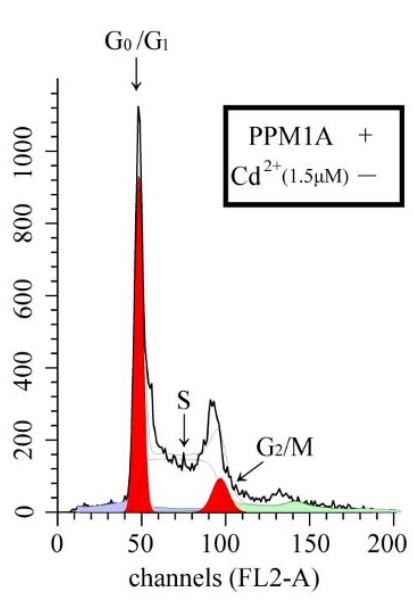

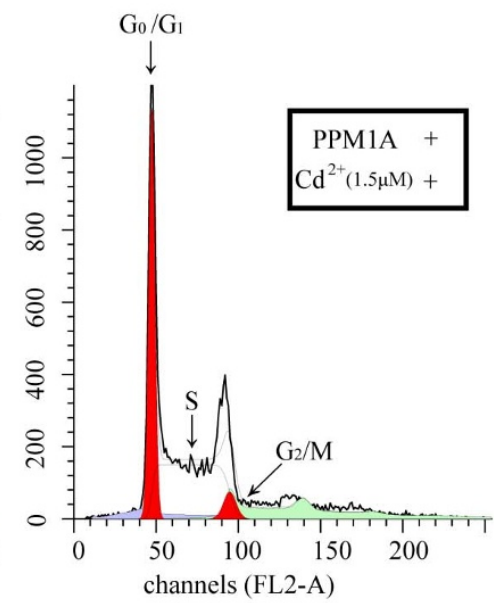

(c)

Figure 6 Cadmium reverses the effect of PPM1A on $\mathrm{G}_{2} /$ M-phase arrest. (a) Representative images of the cell cycle distribution of HEK293 cells in the presence of $\mathrm{CdCl}_{2}$ or overexpressed PPM1A. HEK293 cells transfected with pcDNA3.1-flag-PPM1A were synchronized by serum starvation. The cell cycle was resumed by adding DMEM containing 10\% FBS, and the cells were stimulated with $1.5 \mu \mathrm{M} \mathrm{CdCl}_{2}$ for 24 h. The cells were then analyzed to determine the DNA content by propidium iodide (PI) staining and flow cytometry. Experiments were repeated at least three times. Red peak (left): $\mathrm{G}_{0} / \mathrm{G}_{1}$ fraction of the aneuploid HEK293 cells; small red peak (right): $\mathrm{G}_{2} / \mathrm{M}$ fraction; area between the left red peak and the right red peak: $S$ phase fraction of the aneuploid HEK293 cells. (b) Bar chart showing the percentage of cells in $\mathrm{G}_{2} / \mathrm{M}$ phase. *: PPM1A-overexpressing cells compared with control cells, $\mathrm{P}<0.05$; \#: $\mathrm{Cd}^{2+}$-treated cells compared with untreated cells. $\mathrm{P}<0.05$. (c) Western blot results for the overexpression of PPM1A in transfected HEK293 cells. Flag-PPM1A protein expression was detected by the M1-Flag antibody.

phosphorylation $^{29,34}$. Therefore, we tested the inhibitory activity of $\mathrm{Cd}^{2+}$ on PPM1A in EGF-stimulated ERK signaling in HEK293 cells. The overexpression of PPM1A resulted in a reduction of ERK phosphorylation at the $\mathrm{pT}^{202} / \mathrm{pY}^{204}$ site by half. This effect could be reversed by adding $1.5 \mu \mathrm{M} \mathrm{Cd}^{2+}$ (Fig. $5 \mathrm{~d}$ and $5 \mathrm{e}$ ).

Next, we accessed the inhibitory effects of $\mathrm{Cd}^{2+}$ on PPM1G. Previous studies have revealed that PPM1G positively promotes AKT phosphorylation ${ }^{35}$. As predicted, the overexpression of PPM1G promoted AKT phosphorylation at $\mathrm{pT}^{473}$. When $1.5 \mu \mathrm{M}$ $\mathrm{Cd}^{2+}$ was added, the effect of PPM1G on AKT phosphorylation was completely blocked (Fig. $5 \mathrm{f}$ and $5 \mathrm{~g}$ ).

To verify that the effects of $\mathrm{Cd}^{2+}$ on MAPK phosphorylation cascades are mediated through the inhibition of PPM1A and not nonspecific interactions with other cellular components, we utilized the $\mathrm{Cd}^{2+}$ insensitive D239K mutant of PPM1A, which was identified in in vitro enzymology studies. Although $\mathrm{D} 239 \mathrm{~K}$ had a lower $\mathrm{k}_{\mathrm{cat}}$ for the small artificial substrate pNPP, the overexpression of D239K by 5 fold relative to endogenous PPM1A still significantly blocked sorbitol-induced P38 and JNK-1 phosphorylation (Fig. 5g). In contrast to the results for the wild-type enzyme, for which $1.5 \mu \mathrm{M} \mathrm{Cd}^{2+}$ reversed the decreased P38 and JNK-1 phosphorylation, $1.5 \mu \mathrm{M} \mathrm{Cd}^{2+}$ had much weaker effects on the D239K mutant of PPM1A (Fig. 5g, 5h and 5i). Therefore, a low micromolar concentration of $\mathrm{Cd}^{2+}$ antagonizes the MAPK phosphorylation cascade by directly inhibiting PPM family phosphatases in cells.

Cadmium reverses the function of PPM1A on cell cycle and D239K mutant of PPM1A rescued cadmium-induced PC12 cell apoptosis. PPM1A regulates multiple cellular functions, such as the stress response, apoptosis, and cell cycle progression ${ }^{34,36}$. To further validate the regulatory effect of $\mathrm{Cd}^{2+}$ on the function of PPM1A, we firstly assessed the effect of $\mathrm{Cd}^{2+}$ on the cell cycle in HEK293 cells. The overexpression of PPM1A in HEK293 cells led to the pronounced accumulation of cells in $\mathrm{G}_{2} / \mathrm{M}$ phase, with an approximately 100\% increase compared with control cells (Fig. 6a and 6b). The addition of $1.5 \mu \mathrm{M} \mathrm{Cd}^{2+}$ greatly reversed the increase in the proportion of cells in $\mathrm{G}_{2} / \mathrm{M}$. We next monitored the effect of $\mathrm{Cd}^{2+}$ on apoptosis. Similar to previous observation, application of 1.5 or $2.5 \mu \mathrm{M} \mathrm{Cd}{ }^{2+}$ induced PC12 cell apoptosis ${ }^{37}$. While $\mathrm{Cd}^{2+}$ did not promote PC12 cell apoptosis with the overexpression of the $\mathrm{Cd}^{2+}$ insensitive mutant $\mathrm{D} 239 \mathrm{~K}$, validating the concept that $\mathrm{Cd}^{2+}$ can regulate PPM1A functioning by inhibiting its activity in cells (Supplemental Fig. S5).

\section{Discussion}

Cadmium is a non-degradable heavy metal with a long biological half-life (15-30 years). Long-term exposure to the cadmium results in its accumulation in human organs, leading to different diseases, such as hypertension, cancer, organ dysfunction, immune or neuronal system disorders. However, the mechanism underlying the toxicity of cadmium is complicated due to its multiple cellular targets, and exposure of cadmium with different durations or concentrations produce distinct cellular phenotypes. For example, $0.1 \sim 10 \mu \mathrm{M}$ cadmium exposure cause cell apoptosis, while higher concentration of cadmium results in necrosis ${ }^{8}$. One reason for these observations is the different affinity of cadmium for metal proteins. Therefore, elucidation of the cadmium interacting proteins and their affinity for cadmium are important in understanding the toxic mechanism of cadmium. 
Numerous studies have found that cadmium exposure altered phosphorylation cascades. However, its underlying mechanism remains elusive. Recent studies have disclosed that cadmium regulated protein phosphorylation through diminution of the protein levels of PP5 and PP2A-A subunit ${ }^{21}$. However, whether the cadmium could perturb the phosphorylation cascades through directly acting on phosphatases, have never been investigated.

In this study, we unexpectedly uncovered that cadmium potently inhibited two PPM phosphatase members, PPM1A and PPM1G (Fig. $1 \mathrm{~b}$ and 1c). In contrast, cadmium did not inhibit the Ser/Thr phosphatase PP1 and PP2A, or other tyrosine phosphatases in the low micromolar range (Fig. 2c,4a and S4). In cells, application of $1.5 \mu \mathrm{M}$ cadmium arrested the effects of PPM1A on MAPK signaling, while it has no effect for the cadmium insensitive PPM1A mutant, the D239K, identified through mutagenesis and kinetic studies in vitro (Fig. 5). Application of cadmium insensitive mutant D239K of PPM1A rescued cadmium induced apoptosis, similar to the effect of overexpression of PP2A (Supplemental Fig. S5) ${ }^{21}$. While previous studies identified that cadmium regulated phosphorylation cascades through decreasing the protein level of PP2A or PP5, our results revealed a new mechanism of cadmium action, through direct interacting and blocking PPM phosphatases.

All PPM phosphatases have two metal ion centers which are required for their activity. Through the examination of 27 mutations in the active site of PPM1A and PPM1G, we revealed that cadmium inhibits PPM phosphatases through the M1 metal ion binding site (Fig. 3). In particular, the negative charge of the conserved D441 residue in PPM1G is involved in the specific recognition of cadmium, but is not required for manganese binding. In addition to cadmium, removing the negative charge by $\mathrm{D} 441 \mathrm{~N}$ also decreased the binding of PPM1G to $\mathrm{Zn}^{2+}, \mathrm{Ca}^{2+}$ and $\mathrm{Sr}^{2+}$. Conversely, D441N mutant increased its binding to $\mathrm{Hg}^{2+}, \mathrm{Cr}^{2+}$ and $\mathrm{Li}^{+}$(Fig. 3f and g). Among all metal ions tested, cadmium exhibits strongest binding to wild type PPM1G, with $\mathrm{K}_{\mathrm{i}}$ of $170 \mathrm{nM}$ (Fig. 1). While the D441N mutant changed its metal ion inhibition profiles. Its strongest inhibitor was $\mathrm{Hg}^{2+}$, instead of $\mathrm{Cd}^{2+}$ (Fig. 3f). Therefore, both the shape and the property of the metal ion coordinated residues in the active site of PPM phosphatases defined the selectivity for the metal ions, and other residues may also contribute to specific recognition of the cadmium. Further biochemical characterization or complex crystal structure of cadmium with the PPM phosphatase could provide details for cadmium recognition.

Moreover, among the 9 mutations of the conserved active site residues that mimic the different PPM phosphatase family members (R33K, R33N, E37C, E37L, D38K, D38V, D239K and G240A in PPM1A and E40Q in PPM1G), only D239K drastically decreased the $\mathrm{Cd}^{2+}$ inhibitory activity (Fig. 3e and Table 1). The phosphatases corresponding to the D239K mutation are PHLPP1 and PHLPP2, indicating that these phosphatases may be less sensitive to inhibition by $\mathrm{Cd}^{2+}$ (Fig. 3e). Consistent with this hypothesis, the $\mathrm{IC}_{50}$ of $\mathrm{Cd}^{2+}$ for the PHLPP2 catalytic domain was $3 \mathrm{mM}$, 4 orders of magnitude higher than the $\mathrm{IC}_{50}$ values for PPM1A and PPM1G (Supplemental Fig. S3). With the exception of D239, all other residues in the M1 metal ion binding site are identical among the 17 PPM phosphatase members. Thus, we hypothesized that $\mathrm{Cd}^{2+}$ might be a general potent inhibitor of most PPM phosphatase family members except for PHLPP1 and PHLPP2.

Taken together, our results revealed a novel effect of cadmium on PPM phosphatases. These findings provide a better understanding of the effects of metal ions on PPM phosphatases and the toxicity of cadmium in the contexts of human physiology and pathology.

\section{Methods}

Materials. Para-nitrophenyl phosphate (pNPP, 4264-83-9) was obtained from Sangon Biotech Co., Ltd. (Shanghai, China). The phospho-peptides derived from ppERK2 (TGFLpT ${ }^{202} \mathrm{EpY}^{204}$ VATR) and pp-P38 (TDDEMpT ${ }^{180} \mathrm{GpY}^{182} \mathrm{VAT}$ ) were purchased from China Peptides Co. (China). The BIOMOL Green ${ }^{\mathrm{TM}}$ Reagent for
Phosphate Detection, BML-AK111, was from Enzo Life Sciences. The Ni-NTA agarose was from Amersham Pharmacia Biotech. The His-probe (H-3) HRP antibody and p-JNK (G-7) ( $\left.\mathrm{pT}^{183} / \mathrm{pY}^{185}\right)$ antibody were from Santa Cruz Biotechnology. The DYKDDDDK Tag antibody, the P-p38 MAPK ( $\mathrm{pT}^{180} / \mathrm{pY}^{182}$ ) antibody, the phosphoAkt $\left(\mathrm{Ser}^{473}\right)$ antibody and the P-p44/42 MAPK (ERKpT $\left.{ }^{202} / \mathrm{pY}^{204}\right)$ antibody were purchased from Cell Signaling Technology. $\mathrm{CdCl}_{2}, \mathrm{MnCl}_{2}, \mathrm{MgCl}_{2}$, and most other chemicals were obtained from Sangon Biotech (Shanghai) Co. and Sigma. PP2A protein were from Millipore.

Mutagenesis and constructs. The full-length human PPM1A cDNA was a generous gift from Professor Patricia T. W. Cohen at the MRC Protein Phosphorylation Unit, University of Dundee, Scotland. The cDNAs of human PPM1A, PPM1G and PHLPP2 (catalytic domain, residues 784-1033) were subcloned into the PET-30a expression vector with an N-terminal His tag, as described in a previous paper ${ }^{38}$. To express PPM1A and PPM1G in mammalian cells, human full-length wild-type PPM1A and PPM1G were subcloned into the pcDNA3.1 vector containing an Nterminal Flag tag. The PPM1A mutants (R33A, R33N, R33K, E37A, E37C, E37L, D38A, D38K, D38V, D60A, D60N, G61A, D239A, D239K, G240A and D282A) and PPM1G mutants (R36A, E40A, E40Q, D60A, D60N, H62A, H62N, D441A, D441N, D496A and D496N) were generated using the QuikChange mutagenesis kit obtained from Stratagene ${ }^{39}$. The PAGE-purified oligonucleotide primers were purchased from Beijing Genomics Institute (China). All PPM mutations were verified by DNA sequencing.

Phosphatase Assays. Para-nitrophenyl phosphate (pNPP, Bio Basic) was used in enzymatic reactions to determine the intrinsic catalytic activities of PPM1A, PPM1G and their mutants ${ }^{40}$. All assays using pNPP as the substrate were performed in a reaction buffer containing $0.05 \mathrm{M}$ Tris, $0.05 \mathrm{M}$ Bis-Tris and $0.1 \mathrm{M}$ acetate at $25^{\circ} \mathrm{C}$, $\mathrm{pH}$ 8.0. To determine the $\mathrm{k}_{\mathrm{cat}}$ and $\mathrm{k}_{\mathrm{cat}} / \mathrm{K}_{\mathrm{m}}$ values, the initial rates were measured at various substrate or pseudo-substrate concentrations. The enzyme-catalyzed dephosphorylation was halted by the addition of $0.5 \mathrm{M}$ EDTA, $\mathrm{pH} 10.0$, and the catalytic activity was detected by monitoring the absorbance of para-nitrophenol at $405 \mathrm{~nm}$. Initial linear rates were determined using the molar extinction coefficient $(\varepsilon)$ of $16.3 \mathrm{mM}^{-1} \mathrm{~cm}^{-1}$ for the product p-nitrophenol (pNP) at $405 \mathrm{~nm}$ at $\mathrm{pH}$ 8.0. The acquired data were fitted to Equation 1 with GraphPad Prism software.

$$
v=\frac{\mathrm{k}_{\mathrm{cat}} * S}{\mathrm{~K}_{\mathrm{m}}+S}
$$

In our study, $\mathrm{Mn}^{2+}$ was used for the majority of the kinetic studies because of its high specific activity and relative stability. $\mathrm{Fe}^{2+}$ was largely avoided because it is easily oxidized. To determine the kinetic parameters $\mathrm{k}_{\text {cat }}$ and $\mathrm{K}_{\text {metal }}, \mathrm{Mn}^{2+}$ concentrations ranging from 1 to $100 \mathrm{mM}$ were used under saturating concentrations of pNPP (10$40 \mathrm{mM})$.

Cadmium inhibition assay. The $\mathrm{K}_{\mathrm{i}}$ values for the inhibition of PPM1A, PPM1G and mutants by $\mathrm{Cd}^{2+}$ were measured using pNPP as the substrate in a buffer containing $0.05 \mathrm{M}$ Tris, $0.05 \mathrm{M}$ Bis-Tris and $0.1 \mathrm{M}$ acetate at $25^{\circ} \mathrm{C}, \mathrm{pH} 8.0$, and varying concentrations of $\mathrm{MnCl}_{2}$. The data were fitted to the Lineweaver-Burk equation

$$
\begin{aligned}
& 1 / \mathrm{V}=\left(\mathrm{K}_{\mathrm{m}}+[\mathrm{S}]\right) /\left(\mathrm{V}_{\max } *[\mathrm{~S}]\right) \\
& =\left(\mathrm{K}_{\mathrm{m}} / \mathrm{V}_{\max }\right) *(1 /[\mathrm{S}])+1 / \mathrm{V}_{\max }
\end{aligned}
$$

Dephosphorylation of Protein Substrates in vitro. The dephosphorylation of a recombinant phosphorylated ERK2 protein by PPM1A, D239K or D282A mutant of PPM1A, and PPM1G was performed in a reaction buffer containing $0.05 \mathrm{M}$ Tris, $0.05 \mathrm{M}$ Bis-Tris, $0.1 \mathrm{M}$ acetate and suitable $\mathrm{Mn}^{2+}$ at $37^{\circ} \mathrm{C}, \mathrm{pH} 8.0$, with or without $1.5 \mu \mathrm{M} \mathrm{Cd}^{2+}$. The PPM1A/PPM1G-catalyzed p-ERK dephosphorylation was halted by boiling in SDS buffer at $100^{\circ} \mathrm{C}$ for $10 \mathrm{~min}$, and the extent of the reaction was analyzed by Western blotting with an anti-ppERK-pT ${ }^{202} \mathrm{pY}^{204}$ antibody.

Cell Culture, Transfection, and Immunoblotting. Human kidney 293 cells were cultured in DMEM supplemented with $25 \mathrm{mM}$ glucose, $10 \%$ fetal bovine serum, and $1 \%$ penicillin/streptomycin ${ }^{41}$ in a humidified incubator at $37^{\circ} \mathrm{C}$ with $5 \% \mathrm{CO}_{2}$. The full-length wild-type PPM1A, PPM1G and D239K mutant sequences were subcloned into the pcDNA3.1/flag plasmid, and HEK293 cells were transfected with these plasmids using Lipofectamine 2000 (Invitrogen). At 36 hours after transfection and after 12 hours of starvation, the cells were incubated with $1.5 \mu \mathrm{M} \mathrm{CdCl}_{2}$ for 6 hours and then stimulated with $5 \mathrm{ng} / \mathrm{ml} \mathrm{EGF}$ for $5 \mathrm{~min}$ or $0.4 \mathrm{M}$ sorbitol at $37^{\circ} \mathrm{C}$. Subsequently, the cells were washed twice with cold PBS and then collected in cold lysis buffer (50 mM Tris, pH 7.5, $150 \mathrm{mM} \mathrm{NaCl}, 1 \%$ Triton X-100, 1 mM EGTA, $1 \mathrm{mM} \mathrm{Na}_{3} \mathrm{VO}_{4}, 50 \mathrm{mM} \mathrm{NaF}, 0.25 \%(\mathrm{~m} / \mathrm{v})$ sodium deoxycholate, $10 \%(\mathrm{v} / \mathrm{v})$ glycerol, protease inhibitor cocktail tablet and $5 \mathrm{mM} \mathrm{IAA})^{19}$. The cells were lysed on ice for $30 \mathrm{~min}$ and then centrifuged at $12000 \mathrm{rpm}$ for $20 \mathrm{~min}$ at $4^{\circ} \mathrm{C}$. The protein concentrations of the samples were determined using the BCA Protein Quantitation Kit. Equal amounts of lysate proteins were denatured in $2 \times$ SDS loading buffer and then boiled for $10 \mathrm{~min}$. The cell lysates were subjected to SDS-PAGE, transferred to a nitrocellulose membrane and immunoblotted with the appropriate antibodies.

Cell Cycle Assay. HEK293 cells were cultured in DMEM containing 10\% fetal bovine serum and antibiotics in a humidified incubator at $37^{\circ} \mathrm{C}$ with $5 \% \mathrm{CO}_{2}$. The cells were seeded at $1.5^{*} 10^{6}$ cells per $6 \mathrm{~cm}$ plate. At 36 hours after transfection with the PPM1A 
construct and after 12 hours of starvation, the cells were incubated with $1.5 \mu \mathrm{M} \mathrm{CdCl}_{2}$ for 24 hours. Then, the cell cycle was resumed by adding medium containing $10 \%$ FBS. The cells were harvested, fixed with $75 \%$ ethanol at $4^{\circ} \mathrm{C}$ overnight, and resuspended in phosphate-buffered saline containing $0.1 \% \mathrm{NaN}_{3}$. Propidium iodide $(50 \mu \mathrm{g} / \mathrm{ml})$ was added for nuclear staining, and the cells were analyzed using a fluorescence-activated cell sorter (FACS Calibur, Becton Dickinson).

Data analysis. The data analysis was conducted with ImageJ software, GraphPad Prism 5 software, ModFit LT software and WinMDI 2.9 software. All data are presented as the mean \pm standard error, and statistical comparisons were made with ANOVA and a two-tailed Student's $t$-test using GraphPad Prism 5.

1. Joseph, P., Lei, Y. X. \& Ong, T. M. Up-regulation of expression of translation factors--a novel molecular mechanism for cadmium carcinogenesis. Mol Cell Biochem 255, 93-101 (2004).

2. Nogawa, K., Kobayashi, E., Okubo, Y. \& Suwazono, Y. Environmental cadmium exposure, adverse effects and preventive measures in Japan. Biometals 17, 581-587 (2004).

3. Zhang, X. et al. Impacts of lead/zinc mining and smelting on the environment and human health in China. Environ Monit Assess 184, 2261-2273 (2012).

4. Kopp, S. J., Glonek, T. \& Greiner, J. V. Interspecies variations in mammalian lens metabolites as detected by phosphorus-31 nuclear magnetic resonance. Science 215, 1622-1625 (1982)

5. Haase, H., Ober-Blobaum, J. L., Engelhardt, G., Hebel, S. \& Rink, L. Cadmium ions induce monocytic production of tumor necrosis factor-alpha by inhibiting mitogen activated protein kinase dephosphorylation. Toxicol Lett 198, 152-158 (2010).

6. Luparello, C., Sirchia, R. \& Longo, A. Cadmium as a transcriptional modulator in human cells. Crit Rev Toxicol 41, 75-82 (2011).

7. Lane, T. W. et al. Biochemistry: a cadmium enzyme from a marine diatom. Nature 435, 42 (2005)

8. Michalek, J. L., Lee, S. J. \& Michel, S. L. Cadmium coordination to the zinc binding domains of the non-classical zinc finger protein Tristetraprolin affects RNA binding selectivity. Journal of inorganic biochemistry 112, 32-38 (2012).

9. Son, Y. O. et al. Cadmium induces intracellular $\mathrm{Ca} 2+-$ and $\mathrm{H} 2 \mathrm{O} 2$-dependent apoptosis through JNK- and p53-mediated pathways in skin epidermal cell line. Toxicol Sci 113, 127-137 (2010).

10. Swandulla, D. \& Armstrong, C. M. Calcium channel block by cadmium in chicken sensory neurons. Proc Natl Acad Sci U S A 86, 1736-1740 (1989).

11. Xie, Z. et al. Cd-induced apoptosis was mediated by the release of $\mathrm{Ca} 2+$ from intracellular Ca storage. Toxicol Lett 192, 115-118 (2010).

12. Xu, B. et al. Calcium signaling is involved in cadmium-induced neuronal apoptosis via induction of reactive oxygen species and activation of MAPK/ mTOR network. PLoS One 6, e19052 (2011).

13. Templeton, D. M. \& Liu, Y. Multiple roles of cadmium in cell death and survival. Chem Biol Interact 188, 267-275 (2010).

14. Martin, P. \& Pognonec, P. ERK and cell death: cadmium toxicity, sustained ERK activation and cell death. FEBS J 277, 39-46 (2010).

15. Martin, P., Boulukos, K. E., Poggi, M. C. \& Pognonec, P. Long-term extracellular signal-related kinase activation following cadmium intoxication is negatively regulated by a protein kinase $\mathrm{C}$-dependent pathway affecting cadmium transport. FEBS J 276, 1667-1679 (2009).

16. Siu, E. R., Mruk, D. D., Porto, C. S. \& Cheng, C. Y. Cadmium-induced testicular injury. Toxicol Appl Pharmacol 238, 240-249 (2009).

17. Nemmiche, S., Chabane-Sari, D., Kadri, M. \& Guiraud, P. Cadmium-induced apoptosis in the BJAB human B cell line: involvement of PKC/ERK1/2/JNK signaling pathways in HO-1 expression. Toxicology 300, 103-111 (2012).

18. Liu, J. et al. Biochemical and Functional Studies of Lymphoid-Specific Tyrosine Phosphatase (Lyp) Variants S201F and R266W. PLoS One 7, e43631 (2012).

19. Yu, X. et al. Substrate specificity of lymphoid-specific tyrosine phosphatase (Lyp) and identification of Src kinase-associated protein of $55 \mathrm{kDa}$ homolog (SKAPHOM) as a Lyp substrate. J Biol Chem 286, 30526-30534 (2011).

20. Sun, J. P. et al. Phosphatase activity, trimerization, and the C-terminal polybasic region are all required for PRL1-mediated cell growth and migration.J Biol Chem 282, 29043-29051 (2007)

21. Chen, L., Liu, L. \& Huang, S. Cadmium activates the mitogen-activated protein kinase (MAPK) pathway via induction of reactive oxygen species and inhibition of protein phosphatases 2A and 5. Free Radic Biol Med 45, 1035-1044 (2008).

22. Das, A. K., Helps, N. R., Cohen, P. T. \& Barford, D. Crystal structure of the protein serine/threonine phosphatase $2 \mathrm{C}$ at 2.0 A resolution. EMBO J 15, 6798-6809 (1996)

23. Fjeld, C. C. \& Denu, J. M. Kinetic analysis of human serine/threonine protein phosphatase 2Calpha. J Biol Chem 274, 20336-20343 (1999).

24. Godat, L. N. et al. Recurrence after mastectomy for ductal carcinoma in situ. Am Surg 75, 592-597 (2009).

25. Shi, Y. Serine/threonine phosphatases: mechanism through structure. Cell 139, 468-484 (2009).

26. Wehenkel, A., Bellinzoni, M., Schaeffer, F., Villarino, A. \& Alzari, P. M. Structural and binding studies of the three-metal center in two mycobacterial PPM Ser/Thr protein phosphatases. J Mol Biol 374, 890-898 (2007).
27. Jackson, M. D., Fjeld, C. C. \& Denu, J. M. Probing the function of conserved residues in the serine/threonine phosphatase PP2Calpha. Biochemistry 42, 8513-8521 (2003).

28. Chen, M., Sun, J. P., Liu, J. \& Yu, X. Research progress of several protein tyrosine phosphatases in diabetes. Sheng Li Xue Bao 62, 179-189 (2010).

29. Li, R. et al. Metal-dependent protein phosphatase $1 \mathrm{~A}$ functions as an extracellular signal-regulated kinase phosphatase. FEBS J (2013).

30. Zhou, B., Wang, Z. X., Zhao, Y., Brautigan, D. L. \& Zhang, Z. Y. The specificity of extracellular signal-regulated kinase 2 dephosphorylation by protein phosphatases. J Biol Chem 277, 31818-31825 (2002).

31. Junttila, M. R., Li, S. P. \& Westermarck, J. Phosphatase-mediated crosstalk between MAPK signaling pathways in the regulation of cell survival. FASEB J 22, 954-965 (2008).

32. Paul, S., Nairn, A. C., Wang, P. \& Lombroso, P. J. NMDA-mediated activation of the tyrosine phosphatase STEP regulates the duration of ERK signaling. Nat Neurosci 6, 34-42 (2003).

33. Takekawa, M., Maeda, T. \& Saito, H. Protein phosphatase 2Calpha inhibits the human stress-responsive p38 and JNK MAPK pathways. EMBO J 17, 4744-4752 (1998).

34. Shohat, M., Ben-Meir, D. \& Lavi, S. Protein phosphatase magnesium dependent 1A (PPM1A) plays a role in the differentiation and survival processes of nerve cells. PLoS One 7, e32438 (2012).

35. Suh, E. J., Kim, Y. J. \& Kim, S. H. Protein phosphatase 2Cgamma regulates the level of p21Cip1/WAF1 by Akt signaling. Biochem Biophys Res Commun 386, 467-470 (2009).

36. Ofek, P., Ben-Meir, D., Kariv-Inbal, Z., Oren, M. \& Lavi, S. Cell cycle regulation and p53 activation by protein phosphatase $2 \mathrm{C}$ alpha. J Biol Chem 278, 14299-14305 (2003).

37. Chen, L., Liu, L., Luo, Y. \& Huang, S. MAPK and mTOR pathways are involved in cadmium-induced neuronal apoptosis. J Neurochem 105, 251-261 (2008).

38. Barr, A. J. et al. Large-scale structural analysis of the classical human protein tyrosine phosphatome. Cell 136, 352-363 (2009).

39. Bjorses, P. et al. Mutations in the AIRE gene: effects on subcellular location and transactivation function of the autoimmune polyendocrinopathy-candidiasisectodermal dystrophy protein. American journal of human genetics 66, 378-392 (2000).

40. Frankel, H. H. \& Peters, R. L. A Modified Calcium-Cobalt Method for the Demonstration of Alkaline Phosphatase. The Use of Para-Nitrophenyl Phosphate as a Substrate. Technical bulletin of the Registry of Medical Technologists 34, 134-137 (1964).

41. Yang, W. L. et al. The E3 ligase TRAF6 regulates Akt ubiquitination and activation. Science 325 (2009).

\section{Acknowledgments}

This work was supported by grants from the National Key Basic Research Program of China (2012CB910402 to Dr. J.P.S. and 2013CB967700 to Dr. X.Y.); National Natural Science Foundation of China (31100580, 31271505 to J.P.S.; 31000362 and 31270857 to X.Y.; and 81171062 to Q.P.); the Foundation for Excellent Young and Middle-Aged Scientists of Shandong Province, China (BS2011SW020 to J.P.S.); the Foundation of Program for New Century Excellent Talents in University, China (NCET-09-0531 to X.Y.) and the Independence Innovation Foundation of Shandong University (2012TS114 to J.P.S.);Science And Technology Innovation Fund Projects for Students of Qilu Medical Class from the medical college of Shandong University (No.M2011e02).

\section{Author contributions}

J.P.S., C.P. and X.Y. designed all experiments and W.C. initiated the research for PPM1G; C.P., H.D.L., Z.G., X.B.H., D.D.X., X.B.Z., J.Y.T. and J.Q.Y. performed biochemical, enzymology, cellular and molecular biology experiments; C.P. and Y.F.X. analyzed data; J.P.S.,W.C. and C.P. wrote the paper; X.B.H. and H.F. carried out computer simulation; J.P.S., X.Y., Q.P., H.W.L., L.Y.Z. and Y.G.C. provided funding and made the constructs; K.H.X., J.Y.W. and Q.P. discussed the results and provided essential reagents. All the authors reviewed the paper and agreed for publication.

\section{Additional information}

Supplementary information accompanies this paper at http://www.nature.com/ scientificreports

Competing financial interests: The authors declare no competing financial interests.

How to cite this article: Pan, C. et al. Cadmium is a potent inhibitor of PPM phosphatases and targets the M1 binding site. Sci. Rep. 3, 2333; DOI:10.1038/srep02333 (2013).

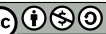

This work is licensed under a Creative Commons AttributionNonCommercial-ShareAlike 3.0 Unported license. To view a copy of this license, visit http://creativecommons.org/licenses/by-nc-sa/3.0 